\title{
Mirar de reojo y fijar la mirada en los textos latinos*
}

\author{
Ma Antònia Fornés PALLICER \\ Universidad de las Islas Baleares \\ mafornes@uib.es \\ Mercè Puig RodríGuEZ-EscAlonA \\ Universidad de Barcelona \\ mercepuig@ub.edu
}

Recibido: 15 de septiembre de 2011

Aceptado: 10 de noviembre de 2011

\section{RESUMEN}

En este artículo se expone una parte de las conclusiones obtenidas en la investigación sobre la gestualidad de los ojos en los textos latinos que se está llevando a cabo en el marco de un estudio más amplio sobre la gestualidad en la Antigüedad romana. A partir del modo de realización del gesto, hemos establecido una clasificación de los gestos realizados con los ojos que comprende dos grandes apartados: los gestos que implican un movimiento de los párpados y aquellos que consisten en un movimiento del iris. Nos centramos en este trabajo en dos gestos pertenecientes a esta segunda categoría: mirar de reojo y fijar los ojos. Analizamos aquí su modo de realización, cómo se refieren a ellos los escritores romanos y los significados que de su uso en los textos se infieren.

Palabras clave: Pragmática. Gestualidad. Ojos. Movimiento del iris.

Fornés Pallicer, Ma A. - Puig Rodríguez-Escalona, M., «Mirar de reojo y fijar la mirada en los textos latinos», Cuad. Fil. Clás. Estud. Lat. 31.2 (2011) 213-234.

\section{Looking sideways and staring in Latin texts}

\begin{abstract}
This article presents some of the conclusions drawn from our research on eye gestures in Latin texts. This investigation is part of a broader study on gestures in Ancient Rome. We have established a classification of eye gestures that comprises two major categories based on the nature of the gestures: gestures that involve eyelid movements and those that consist of iris movements. This paper focuses on two gestures which belong to this second category: looking sideways and staring. We analyse the way these gestures were made, how they were referred to by Roman writers and the meanings that may be inferred from their use in literary texts.
\end{abstract}

Keywords: Pragmatics. Gestures. Eyes. Iris movement.

Fornés Pallicer, Ma A. - Puig Rodríguez-Escalona, M., «Looking sideways and staring in Latin texts», Cuad. Fil. Clás. Estud. Lat. 31.2 (2011) 213-234.

${ }^{*}$ Este trabajo se integra en los proyectos HUM2005-03913 del Ministerio de Educación y Ciencia (cofinanciado por el Fondo Europeo de Desarrollo Regional, FEDER) y FFI2009-10186 (subprograma FILO) del Ministerio de Ciencia e Innovación. 
A la sabiduría popular debemos la idea de que los ojos son el espejo del alma, y es mucho, ciertamente, lo que en ellos podemos leer. La investigación moderna sobre gestualidad precisa esa aseveración: «espejo del alma sí, pero también de la mente, de nuestra identidad y hasta un espejo del mundo» (Poggi 2006, p.85). Y es que, aunque, como es obvio, las funciones básicas de los ojos son las de ver y mirar, con la mirada podemos también comunicar. Del mismo modo se entendió en la Antigüedad romana. ${ }^{1}$ Ciertamente entre los escritores romanos son muchos los que consideran los ojos como el órgano más capaz de expresar los movimientos del alma: Cicerón ${ }^{2}$ (De orat.3.221) afirma que todo el poder de expresión reside en el rostro y que en él detentan el señorío los ojos e insiste en que la cara es la imagen del alma y los ojos son sus indicadores, sed in ore sunt omnia, in eo autem ipso dominatus est omnis oculorum ... imago animi uultus, indices oculi; Plinio (Nat.11.145) considera que en los ojos habita el alma, profecto in oculis animus habitat; Quintiliano (Inst.11.3.75) recoge la misma idea del gran poder que tienen los ojos para comunicar los movimientos del alma, sed in ipso uultu plurimum ualent oculi, per quos maxime animus emanat; e Isidoro (Orig.11.33) manifiesta que, de entre todos los órganos del sentido, los ojos son los más cercanos al alma, oculi ... inter omnes sensus uiciniores animae existunt. En este mismo sentido resulta interesante notar cómo en los tratados de fisiognomía ${ }^{3}$ de la Antigüedad se dedica a la mirada la parte más amplia y articulada, puesto que se considera que los ojos son la zona del cuerpo más rica en signos y la vía más directa de acceso al alma. Así, en el anónimo latino De Physiognomonia 10 leemos: hos (scilicet oculos) enim tamquam fores animae uideri uolunt; nam et animam dicunt per oculos emicare et solum hunc aditum esse per quem animus adiri atque introspici possit ... (Förster 1893, vol. 2, p.17).

En este artículo exponemos una parte de las conclusiones obtenidas en la investigación sobre la gestualidad de los ojos en los textos latinos que estamos llevando a cabo en el marco de una investigación más amplia sobre la gestualidad de la Antigüedad romana.

De hecho, en los últimos años ha cobrado gran auge el estudio de la comunicación no verbal en la Antigüedad griega y latina, un campo que había estado prácticamente abandonado desde la magna obra de Sittl de 1890, y se han publicado numerosos trabajos desde ámbitos diversos como la antropología, el arte, la filología, etc. ${ }^{4}$ Sin em-

\footnotetext{
${ }^{1}$ Para la importancia que los autores romanos daban a los ojos como medio de expresión de los movimientos del alma, $c f$. Evans 1969, pp.5-97, esp. pp.41-42; Rizzini 1998, passim; Aldrete 1999, pp.7 y 32-33; Corbeill 2004, pp.146-148.

${ }^{2}$ Cicerón ya en Orat. 60 se había manifestado igual: Nam ut imago est animi uultus, sic indices oculi.

${ }^{3}$ Los tratados de fisiognomía se proponen deducir las características psicológicas a partir de la observación de los rasgos físicos. Aunque propiamente su objeto de estudio no son los gestos sino los rasgos físicos y, por ello, presentan ciertas dificultades como fuente para extraer conclusiones en nuestro estudio, no obstante, al basarse, en muchos de sus juicios sobre estados permanentes del carácter, en las expresiones faciales de las emociones, confirman el grado de detalle al que habían llegado los antiguos en el análisis de los gestos. $C f$. Evans 1969, pp.5-97; Raina 19942; Rizzini 1998, pp.73-83; y Cairns 2005, pp.123-155, esp. pp.127-128.

${ }^{4}$ Podemos citar, por poner algunos ejemplos, los trabajos de Corbeill 2004 desde el punto de vista de la antropología, de Aldrete 1999, de Brilliant 1999 y de Baggio 2004 en el ámbito del arte o de Lateiner 1995 desde la perspectiva de la proxémica. Asimismo, en el ámbito de la filología, podemos citar los trabajos de Ricottilli 1992 y 2000, Cairns 1993 y 2005, y Rizzini 1998.
} 
bargo, a pesar de esta proliferación de trabajos, se sigue echando en falta un repertorio que recoja todos los gestos que aparecen en los autores latinos y que concrete, por una parte, el modo de realización de cada gesto y, por otra parte, los significados básicos que los romanos les atribuían. La confección de este repertorio constituye el objetivo de nuestra investigación. ${ }^{5}$

Y es que ciertamente los romanos prestaban al gesto mucha atención y en sus obras encontramos numerosas referencias a él, por lo que a partir de los textos podemos intentar precisar su realización y significados básicos. De todas maneras este tipo de aproximación no está exento de dificultades puesto que las referencias al modo de realización del gesto son a menudo vagas e imprecisas y el significado del gesto debe ser deducido por el contexto y su interpretación viene matizada por él. Por ello el estudio del gesto debe incluir una consideración pragmática del mismo, es decir, un análisis de las relaciones del gesto con la situación en que se produce, con la intención del realizador del gesto, con el tipo de relación que existe entre el productor y el destinatario o destinatarios - relación que el gesto refuerza, confirma o modifica - y además con las inferencias que estos últimos están en situación de extraer del gesto, con las que el productor del gesto piensa que pueden extraer, etc. (Ricottilli 2000, p.81).

Antes de centrarnos en el objeto de este artículo, resulta quizá pertinente hacer una breve referencia al marco teórico en que se desarrolla el trabajo. Con referencia a la comunicación humana, se ha distinguido una estructura triple básica: lenguaje-paralenguaje-cinésica. ${ }^{6} \mathrm{~A}$ saber, lo que decimos (el lenguaje verbal, las palabras), cómo lo decimos (el paralenguaje, ${ }^{7}$ toda modificación de la voz y tipos de voz, más las muchísimas emisiones cuasi léxicas independientes) y cómo nos movemos (cinésica). Este último constituyente, que es el que aquí nos ocupa, se ha definido como «movimientos y posiciones de base psicomuscular conscientes o inconscientes, aprendidos o somatogénicos, de percepción visual, audiovisual y táctil o cinestésica, aislados o combinados con la estructura lingüística y paralingüística y con otros sistemas somáticos y objetuales, que comunican intencionadamente o no». ${ }^{8}$

\footnotetext{
${ }^{5}$ Al estudio de la gestualidad en la antigua Roma hemos dedicado numerosos trabajos: Fornés, M.A. -Puig, M. (2004), «Rascar-se l'orella i altres gestos per l'estil», en Usobiaga, B.- Quetglas, P.J. (eds.), Ciència, didàctica i funció social dels estudis clàssics, Barcelona, Promociones y Publicaciones Universitarias S.A., pp.207218; (2005) «La gestualidad facial según los textos latinos: gestos realizados con la boca», en Conde Parrado, P.P.-Velázquez, I. (eds.), La Filología Latina. Mil años más, Madrid, Sociedad de Estudios Latinos, pp.330357; (2005) «Los gestos de burla en la Roma antigua y hoy», Minerva 18, 137-151; (2005) «La gestualidad de la barba y el mentón en la Antigüedad romana», ReLat 5, 175-192; (2005) «El beso al moribundo», en $A c$ tas del XI Congreso de la Sociedad Española de Estudios Clásicos, Madrid, Sociedad Española de Estudios Clásicos, vol. II, pp.833-838; (2005) «El beso a distancia según los textos latinos», Actas del XI Congreso de la Sociedad Española de Estudios Clásicos, Madrid, Sociedad Española de Estudios Clásicos, vol. II, pp.919926; (2006) «Los gestos con el pulgar en los combates de gladiadores», Latomus 65 fasc. 4, 963-971; (2008) El porqué de nuestros gestos. La Roma de ayer en la gestualidad de hoy, Barcelona, Editorial Octaedro - Edicions UIB; (2010) «Apartar y girar los ojos en los textos latinos», Myrtia 25, 77-96. Igualmente Puig, M. (2007), «La gestualidad facial según los textos latinos: gestos y maneras asociados a la nariz», Latomus, 66, 67-79. En el momento de entregar este artículo para su publicación estamos ultimando un estudio sobre los gestos realizados con los párpados en los textos latinos.

${ }^{6}$ Poyatos (1994, esp. vol. 1, pp.129-130) y (2004, p.60).

${ }^{7}$ Poyatos (1994, vol. 1, p.137) y (2004, pp.62-65).

${ }^{8}$ Poyatos (2004, p.65).
} 
La cinésica está, a su vez, integrada por lo que se ha venido en llamar gestos, maneras y posturas. ${ }^{9}$ Las posturas son estáticas, conscientes o inconscientes, ritualizadas, y comunican el sexo, la posición social, el estado de ánimo, el origen cultural, etc. Entre la postura y el gesto se sitúan las maneras, es decir, 'la manera' cómo se realiza un gesto o postura según cultura, sexo, nivel socioeducacional, estado de ánimo, etc. Las maneras pueden ser más o menos conscientes y más o menos dinámicas, son principalmente aprendidas y ritualizadas socialmente según el contexto situacional; asimismo, alternan con las palabras o son simultáneas a ellas.

Llegados a este punto, es necesario, dado que existen entre los estudiosos discrepancias importantes respecto al concepto de gesto, establecer la definición de la que partimos en nuestro análisis. Entendemos por gesto un comportamiento corporal o facial que asuma un valor comunicativo en relación con un destinatario directo o un eventual observador, y para el cual exista una posibilidad de control por parte del emisor. Incluimos, por tanto, en el concepto de 'gesto' los movimientos faciales, esto es, de la boca, los dientes, la barbilla, la frente, las cejas o los ojos. ${ }^{10}$ Como ya hemos dicho, estos últimos nos ocuparán en este trabajo. ${ }^{11}$

Siguiendo esta definición, aunque sí se consideran en los estudios actuales de comunicación no verbal de los ojos, no hemos tenido en cuenta en nuestro trabajo la brillantez y la humedad de los ojos por no tratarse propiamente de gestos sino de reacciones fisiológicas producidas por una fuerte emoción, comportamientos sintomáticos que, en general, no podemos dominar. Además, al considerar el significado de los gestos, hemos soslayado aquellos actos que tienen escaso o nulo valor comunicativo (por ejemplo, fijar la mirada en un objeto para verlo mejor o cerrar los ojos como indicador del sueño), teniendo en cuenta solo los que asumen una función comunicativa. ${ }^{12}$

Por otro lado, dentro de los gestos se han establecido diversas subcategorías, ${ }^{13}$ desde la más tradicional y aceptada de Ekman - Friesen (1969), que distinguen cinco tipos de actos no verbales (emblemas, ilustradores, reguladores, adaptadores y manifestaciones de estado de ánimo), hasta la tipología de diecisiete categorías no-verbales elaborada por Poyatos (1994). Por su significado, los gestos analizados en este artículo pertenecen, básicamente, a tres tipos. La mayoría, como sucede generalmente con los gestos faciales, puede incluirse en el grupo de gestos con valor comunicativo-expresivo, que corresponde a las manifestaciones de estado de ánimo («affect displays»)

\footnotetext{
${ }^{9}$ Para la distinción entre gestos, maneras y posturas, $c f$. Poyatos (1994, vol. 2, p.201) y (2004, pp.65-66).

10 Seguimos de cerca la definición de Ricottilli (2000, p.16), quien señala por otra parte $(2000$, p.13) que los estudiosos deben aún definir la delimitación del concepto de 'gesto', que oscila entre definiciones extremadamente amplias y otras demasiado limitadas. Asimismo Baggio (2004, p.XIV) define el gesto como «il movimento di una o più parti del corpo (braccio, mano, capo) che compie un'azione oppure manifesta delle disposizioni interiori, siano essi sentimenti pensieri o intenzioni, comunicando un messaggio».

11 Vale la pena recordar que también para Cicerón (Orat.55) estaban unidas la gestualidad facial y la gestualidad corporal: dicere etiam de gestu, cum quo iunctus est uultus. Cf. Baggio (2004, p.4) y Ricottilli (2000, p.17)

12 Sobre la función comunicativa y no comunicativa de los ojos, apuntan Poggi y Roberto (2007, pp.325341): «Of course, gaze does not always have a communicative function. Various organs in the human body perform different functions, both communicative an non-communicative: we use our mouth primarily to breath and to eat, our hands firstly to grasp, manipulate or build objects, and only in some cases to communicate. So do we for eyes: we use them for five different functions: seeing, looking, feeling, thinking, and communicating.»

${ }^{13}$ Sobre las clasificaciones de los gestos, $c f$. Kendon (2004), pp.84-107.
} 
de Ekmann y Friesen, esto es, gestos que exteriorizan sentimientos o emociones. En segundo lugar, distinguimos el valor demostrativo o deíctico, a saber, el uso de un gesto para señalar; este valor del gesto se incluiría en la categoría más amplia de los ilustradores propuesta por Ekmann y Friesen. Finalmente, hallamos el uso del gesto como regulador del discurso, ayudando, por tanto, a mantener y moderar los intercambios orales entre dos o más individuos.

En la investigación de la gestualidad de los ojos, hemos establecido una clasificación inicial a partir del modo de realización del gesto y, así, hemos distinguido entre los gestos que consisten en un movimiento de los párpados, como, por ejemplo, guiñar el ojo o parpadear, y aquellos que implican un movimiento del iris. Nos centramos en este trabajo en dos gestos correspondientes a esta segunda categoría: mirar de reojo y fijar los ojos. ${ }^{14}$

\section{MIRAR DE REOJO}

Mirar de reojo consiste, como es bien sabido, en mirar hacia un lado dirigiendo la vista desde el extremo de los ojos. Podemos decir, pues, que se trata de una manera de mirar no directamente, a menudo con intención de disimulo. Los textos latinos constatan su uso entre los romanos aunque no ofrecen un número elevado de ejemplos. En latín se expresa principalmente utilizando los adjetivos limus, - $a$, -um (o limis, -e), incluso en diminutivo limulus, - $a$, -um, y obliquus, - $a$, -um en diferentes combinaciones, como por ejemplo limis (oculis / ocellis) aspicere / contuere / spectare, obliquum respicere / intuere, obliqua tuere, obliquis oculis spectare, obliquo lumine respectare / cernere, así como también con el verbo obliquare, derivado de obliquus, y el sustantivo oculos como complemento directo. ${ }^{15}$ En escasas ocasiones los textos nos describen el movimiento de cabeza que puede acompañar o no al gesto.

Como decíamos, mirar de reojo es una forma de ver algo con disimulo, con la intención de que los demás no perciban que se está mirando. ${ }^{16}$ Ello puede apreciarse claramente en el siguiente pasaje plautino (Mil.1217) en el que Milfidipa aconseja a Acroteleucia que mire con disimulo al soldado Pirgopolinices para que éste no advierta que lo han visto: MI. Aspicito limis, ne ille nos se sentiat uidere. «MiLfIDIPA. - Míralo de reojo, que no se dé cuenta de que lo vemos.» (González Haba 1996, p.345).

\footnotetext{
14 Para los gestos de apartar y girar los ojos, $c f$. Fornés-Puig (2010).

${ }^{15}$ Cabe advertir que muy frecuentemente las traducciones interpretan que estas expresiones se refieren al gesto de guiñar un ojo aunque el significado de estos adjetivos muestre claramente que se trata del gesto de mirar de reojo.

${ }^{16}$ Cf. Ter.Eun.601-602: ego limis specto / sic per flabellum clanculum «miro de reojo, así, disimuladamente por detrás del abanico». El gramático Donato al comentar dicho pasaje terenciano afirma: limis si nominatiuus est singularis. 'transuersus' significat, si deest 'oculis'; nam 'limis' est transuersus, unde limen quoque dicitur...cum igitur dissimulant se homines uidere quod uident et non recta facie sed transuersa intuentur, limes dicuntur aspicere. Otros ejemplos: Hor.Sat.2.5.51-54: qui testamentum tradet tibi cumque legendum, / abnuere et tabulas a te remouere memento, / sic tamen ut limis rapias quid prima secundo / cera uelit uersu; ApUl.Met.1.12: Ac dum in fimum deiectus obliquo aspectu quid rei sit grabatuli sollertia munitus opperior, uideo mulieres duas altioris aetatis.
} 
No obstante, esta mirada de través puede expresar también sentimientos negativos como la hostilidad, la envidia o el desprecio. ${ }^{17}$ En la literatura latina, un texto de Amiano Marcelino (20.9.2) atestigua la mirada de reojo (limibus oculis contuens) como expresión de hostilidad. Narra el historiador la reacción del emperador Constancio al recibir una carta en la que su primo Juliano le informa que los soldados le han nombrado emperador. La mirada que el emperador dirige entonces a los legados deja patente una indignación tal que les hace temer incluso por su vida:

qui intromissi data potestate offerunt scripta hisque recitatis ultra modum solitae indignationis excanduit imperator, limibusque oculis eos ad usque metum contuens mortis, egredi iussit, nihil post haec percontatus uel audire perpessus.

«Cuando fueron recibidos, le entregaron el escrito. Tras ser leído éste, el emperador se indignó más de lo normal y, mirándoles de reojo de tal modo que temieron por su vida, les ordenó retirarse sin preguntar nada ni permitir oírlos.»

Un pasaje de Horacio (Epist.1.14.37-38) da testimonio del uso de esta mirada como exteriorizadora del odio y la envidia. En efecto, cuando el poeta afirma que en el campo no siente el odio (odio obscuro) y la envidia (morsu) de sus conciudadanos en Roma, utiliza el sintagma obliquo oculo como expresión física de dichas emociones: non istic obliquo oculo mea commoda quisquam / limat, non odio obscuro morsuque uenenat. «Aquí nadie merma mis alegrías con miradas oblicuas, ni las envenena con su odio solapado y sus dentelladas envidiosas.» (Cuatrecasas 1992, p.292).

El desprecio puede ser expresado también, como apuntábamos, mediante una mirada de reojo. Amiano Marcelino (28.4.23) nos proporciona un buen ejemplo de este uso al exponer el comportamiento altanero de algunos hombres al acceder a un cargo. El desprecio, provocado por una soberbia desmedida, con que se mira a los antiguos conocidos se refleja en un esquema gestual descrito en este texto: el individuo camina ceruice tumida, mirando de reojo (obliquato contuetur aspectu). Siguiendo esta descripción, resulta plausible suponer que la mirada va acompañada, en este caso, de un ligero movimiento lateral de la cabeza, de tal modo que el altivo personaje mira a los demás «por encima del hombro»:

Alius cum dignitate licet mediocri, ceruice tumida gradiens notos antea obliquato contuetur aspectu, ut post captas Syracusas existimes reuerti M. Marcellum.

${ }^{17}$ Ejemplos del uso del gesto como expresión de un sentimiento negativo: VERG.Aen.4.362 (auersa tuetur; $c f$. a propósito de este pasaje Fornés-Puig 2010), Petron.113.6 (obliquis trucibusque oculis ...spectabam); Priap.73.1 (obliquis...spectatis ocellis); Ov.Met.2.787-789 (obliquo ... lumine cernens); SEN.Thy.703-706 (toruum et obliquum intuens); PLAUT.Bacch.1130-1131 (uiden limulis...ut intuentur); STAT.Silu.2.6.100-102 (obliquo notat... uultu) y Theb.1.673-675 (obliquare oculos), 3.377 (respectentue ...obliquo limine), 4.606 (tuens obliqua) y 10.887 (obliquo respectans lumine); MART. CAP.1.84 (limis...cernebat). Asimismo, QuINT.Inst.11.3.76, cita la mirada de reojo (limi) entre los movimientos y expresiones de los ojos que el orador debe evitar.

También la literatura griega ofrece ejemplos del gesto con un significado similar: A.R.4.475-476 (desaprobación), Sol. fr. 34 West (fr. 23 Diehl) 4-5 (ira y hostilidad); ANTIP.THESS. Anthologia Graeca 7.531.6 (hostilidad); ANACR. fr. 78 Gentili (417 PMG), 1-2 y THEOC.XX.13 (desprecio). Cf. Sittl (1890, p.83) y Cairns (2005, p.136). 
«Otro, si ha alcanzado alguna dignidad, por mediocre que sea, camina mirando por encima del hombro y observa de reojo a personas que conocía de antes, hasta tal punto que creerías que es Marcelo regresando después de capturar Siracusa.» (Harto Trujillo 2002, p.740).

Igualmente, es el desprecio el sentimiento negativo expresado por la mirada de reojo en el texto que comentamos a continuación, pero, en esta ocasión, se manifiesta a través de la burla. ${ }^{18}$ En un pasaje de Ovidio (Am.3.1.33), la Tragedia y la Elegía, personificadas, debaten para intentar ganarse al poeta. Al finalizar la Tragedia el primer discurso, la Elegía sonríe mirando de reojo antes de empezar a hablar: altera, si memini, limis subrisit ocellis. "La otra, si no recuerdo mal, sonrió mirando de reojo.» (Cristóbal 1989, p.301) ${ }^{19}$ En este pasaje el sentimiento de desprecio y burla se expresa tanto con la mirada de reojo como con la sonrisa burlona. ${ }^{20}$

Por otro lado, la mirada de reojo puede darse igualmente en un contexto de seducción amorosa. En efecto, como ya advierte Propercio (2.15.12), oculi sunt in amore duces, la mirada es primordial en las relaciones amorosas. ${ }^{21}$ Los enamorados usan a menudo el poder comunicativo de los ojos para seducir, para provocar, para llamar la atención del otro, etc. La mirada de reojo que, según los textos analizados, en las relaciones amorosas acostumbra a hacer la mujer, añade al componente amoroso el matiz de disimulo muy ligado al gesto, que la hace más provocativa. ${ }^{22}$ En este sentido ya Quintiliano (Inst.11.3.76) establece la relación entre esta mirada de reojo y el deseo amoroso: (oculi) quadam uoluptate suffusi aut limi et, ut sic dicam, uenerii aut poscentes, «los ojos destilando sensualidad o mirando de reojo y, por así decirlo, llenos de deseo o suplicantes». Y así lo leemos en Apuleyo (Met.2.10), donde el protagonista, sin poder contener más los deseos por su amada Fotis, le da un beso en la nuca, a lo cual ella, ladeando la cabeza (ceruicem intorsit), lo mira de reojo (limis ... oculis), sin duda de forma seductora y provocativa: tum illa ceruicem intorsit et ad me conuersa limis et morsicantibus oculis: «Ella entonces volvió la cabeza y, mirándome de reojo y comiéndome con los ojos, ...»El deseo amoroso, pues, se expresa en Fotis ladeando la cabeza, mirando de reojo y comiéndoselo con los ojos. De hecho,

\footnotetext{
${ }^{18}$ Para el significado de burla de la mirada de reojo entre los antiguos griegos cita Cairns 2005, p.147 n. 45 , al comentarista de Homero, Eust.204.27-28 (Il.2.212), y 206.18-33 (Il.2.217) (Stallbaum 1970, p.166 y pp.167-

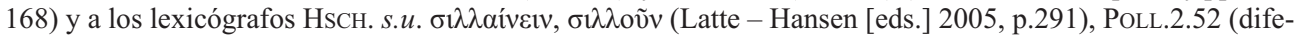

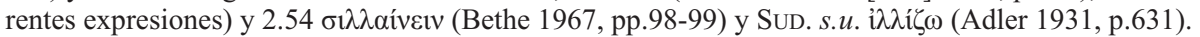

${ }^{19}$ Cf. Bretzigheimer 2001, pp.68-69: «Bei der Elegeia sind es die ocelli, die ihr Wesen spiegeln (limis subrisit ocellis, III 1.33), bei der Tragoedia dagegen ist das Epitheton toruus, das gewöhnlich den Blick kennzeichnent, auf die ganze Stirne übertragen (fronte ... torua, III 1.12)».

${ }^{20}$ Encontramos también la sonrisa burlona en PERS.1.40-41, donde la mofa se expresa además con el gesto de fruncir la nariz: ... rides, ait, et nimis uncis / naribus indulges... Cf. Puig 2007, p.73.

${ }^{21}$ Sobre la relación entre los ojos, el enamoramiento y el deseo sexual en la literatura griega, $c f$. Rizzini 1998, pp.110-126.

${ }^{22}$ La literatura griega también nos ofrece un buen ejemplo del uso de la mirada de reojo en las relaciones amorosas en la Argonáutica de Apolonio de Rodas (3.444-445). Cf. Cairns 2005, p.132, para quien la mirada de reojo que Medea dirige a Jasón se entiende por la ilegitimidad de su amor, y Evans 1950, pp.62-63, donde analiza las técnicas de descripción física en la historia de amor de Jasón y Medea desarrollada en el libro 3 de la Argonáutica.
} 
tras un breve diálogo en el que el protagonista le confirma los deseos que siente por ella, ambos se funden en besos y abrazos.

La expresión del deseo que tiene esta mirada puede apreciarse incluso cuando el receptor no es la persona objeto de dicho deseo. Así, en Estacio, Ach.1.323-324, Tetis, para convencer a su hijo de que se esconda en Esciro disfrazado de doncella, le muestra cómo, si se hace pasar por mujer, podrá vivir su amor con Deidamía en el palacio del rey Licomedes. Ante la perspectiva de colmar sus deseos amorosos, Aquiles enrojece de alegría y mira de reojo a su madre de forma maliciosa (uisus proter$u o s$ ), una mirada que refleja el deseo amoroso que se le aparece en perspectiva: ${ }^{23} \mathrm{mul}$ cetur laetumque rubet uisusque proteruos / obliquat uestesque manu leuiore repellit. «Él se dulcifica, enrojece de alegría y lanza una maliciosa mirada de reojo apartando las ropas con mano insegura.»

Es también esta mirada de reojo -sensual, llena de deseo y suplicante al decir de Quintiliano (Inst.11.3.76)- la que, juntamente con las lágrimas, adopta Venus cuando intenta apaciguar a su amante Marte con el fin de que salve a los tebaidos en Estacio (Theb.3.265-267): ...tunc pectora summo / adclinata iugo uultumque obliqua madentem / incipit... «entonces, con el pecho inclinado sobre el yugo, mirándolo de reojo entre lágrimas, comienza a hablar.»

En otro orden de cosas, se puede mirar de reojo con el propósito de señalar aquello que se está observando, asumiendo así la mirada un valor comunicativo demostrativo. De este modo, la función deíctica de los ojos puede realizarse a través de dos movimientos distintos del iris: por un lado, como veremos más adelante, fijando los ojos en aquello que se pretende señalar; por otro lado, mirando de reojo el objeto sobre el que se quiere llamar la atención. Y es que la llamada mirada deíctica es evidentemente una manera de señalar menos visible que la que podemos realizar con la cabeza, las manos o el dedo índice, y por ello acostumbra a usarse cuando se quiere señalar a alguien o algo de forma menos explícita. Por esta razón, la dirección del iris es a veces distinta a la del rostro, puesto que, mientras quien realiza el gesto se dirige con la cara hacia el interlocutor, con los ojos señala a la persona o el objeto en cuestión, de modo que nadie más pueda advertir la indicación (Poggi 2006, p.95; 2007, pp.279-281). Así pues, en estos casos, el gesto utilizado para señalar es en realidad una mirada de reojo, tal como la describíamos más arriba.

Ello se aprecia claramente en el siguiente pasaje de Estacio (Ach.1.761-766). En el contexto de la estancia de Aquiles en el palacio del rey Licomedes a la que ya nos hemos referido más arriba, se narra la llegada de Ulises y Diomedes a Esciro para encontrar al hijo de Peleo. Hallándose Ulises ante las hijas del rey, entre las cuales estaba Aquiles, busca entre las jóvenes al héroe, lo identifica y con un movimiento del iris (obliquo lumine) lo señala a su compañero Diomedes sin que nadie más lo perciba:

tum uero intentus uultus ac pectora Vlixes perlibrat uisu, sed nox inlataque fallunt

\footnotetext{
${ }^{23}$ Van Dam 1984, p.448, interpreta el gesto considerando que Aquiles no quiere que su madre le vea ruborizándose.
} 
lumina et extemplo latuit mensura iacentum.

at tamen erectumque genas oculisque uagantem

nullaque uirginei seruantem signa pudoris

defigit comitique obliquo lumine monstrat.

«Entonces Ulises examina con mirada atenta los rostros y los pechos, pero la noche y las lámparas allí llevadas le engañan y, tan pronto como se reclinan, su estatura queda oculta. Sin embargo, se fija en una que levanta la cabeza mirando hacia todos lados y que no conserva ninguno de los signos del pudor propio de una doncella y la muestra a su compañero con una mirada de reojo».

A modo de recapitulación, la mirada de reojo, una forma de mirar con disimulo, puede tener un valor comunicativo expresivo en tanto exterioriza, por un lado, sentimientos negativos como la hostilidad, la envidia y el desprecio y, por otro, puede darse en un contexto de seducción amorosa como forma de manifestación del deseo, pues se trata de una mirada sensual y suplicante. En otro orden de cosas, con la mirada de reojo podemos señalar con disimulo y adopta así el gesto un valor comunicativo demostrativo.

\section{FIJAR LOS OJOS}

Fijar los ojos en un objeto con el propósito de verlo con más precisión o bien fijarlos en la persona que habla para entenderla mejor son actos que no comportan ciertamente comunicación no-verbal, pero, en cambio, en otras situaciones, la mirada fija puede constituir un gesto con gran capacidad comunicativa. ${ }^{24}$

El gesto en latín puede expresarse de muchas maneras. Las formas que resultan especialmente aptas para el estudio que realizamos por cuanto no se prestan a ambigüedad en cuanto al significado de fijación visual contienen los verbos figere, y su compuesto defigere, haerere, tenere o tendere y su compuesto intendere, todos ellos llevando como complemento oculos, ocellos, aciem luminum, genas, ora, etc. Para describir el gesto se pueden utilizar igualmente expresiones negativas del tipo non lumina flectere. Además la fijeza del iris puede expresarse calificando el sustantivo oculi con los adjetivos recti, inmobiles o inmoti. Igualmente hemos tenido en cuenta en nuestro trabajo los verbos tueor y sus compuestos intueor, contueor y obtueor 'mirar fijamente' y el substantivo obtutus 'mirada fija' así como contemplor 'mirar atentamente y de grado’ (García Hernández 1976, pp.76-83 y 1996).

$\mathrm{Al}$ analizar el uso del gesto en los textos latinos hemos distinguido dos maneras de fijar los ojos: focalizando la mirada en alguien o en algo o sin focalizarla. En el primer caso el gesto puede funcionar como un regulador del discurso. ${ }^{25}$ Así lo vemos en el verso inicial del libro segundo de la Eneida: Conticuere omnes intentique ora tenebant. «Todos enmudecieron y atentos mantenían el rostro fijo en él.» El auditorio

${ }^{24} C f$. nota 12 .

${ }^{25}$ Según la clasificación establecida por Ekman - Friesen (1969, esp. pp.82-84). 
con su silencio y la mirada fija en el héroe virgiliano le indica que espera el inicio de la narración. ${ }^{26}$

También el emisor de un discurso debe mantener la mirada fija en su auditorio. En este sentido, podemos apuntar que, entre las numerosas observaciones sobre la mirada, los tratados retóricos establecen que los ojos del orador deben fijarse en los de su auditorio con una mirada penetrante, ${ }^{27}$ para que sus palabras ganen en fuerza y eficacia. De hecho, los gestos con los ojos censurados por la oratoria (levantar la mirada, mirar al suelo, girar los ojos en todas direcciones) tienen en común el hecho de que alteran el contacto entre orador e interlocutor, en el cual parece basarse la persuasión (Rizzini 1998, p.67). Se critica, sin embargo, la excesiva fijeza de la mirada (QuINT.Inst.11.3.76), no porque suponga una ruptura del contacto ocular, sino por el exceso de éste, de tal manera que el orador debe encontrar un punto medio entre una movilidad inquieta y una fijeza excesiva de la mirada. Seguramente, la fijeza excesiva de la mirada podía ser interpretada por el destinatario como signo de una actitud agresiva. ${ }^{28}$

El siguiente texto de Estacio (Theb.2.173-175) nos ofrece un ejemplo más de la función de la mirada como reguladora del discurso. ${ }^{29}$ En él, después de haber escuchado cómo el rey Adrasto les revela los dictados del oráculo, Tideo y Polinices se miran mutuamente a los ojos estableciendo un contacto ocular, con el que se ceden el turno de palabra:

audierant, fixosque oculos per mutua paulum

ora tenent, uisique inter sese ordine fandi cedere.

«Lo habían oído y se miran el uno al otro sin mover los ojos durante algún tiempo y parecen cederse mutuamente su turno de palabra.»

En otro orden de cosas, como gesto expresivo-comunicativo fijar los ojos en alguien puede ser indicativo de dominio y superioridad en especial entre individuos de diferente rango. ${ }^{30}$ Sin duda, mirar directa y fijamente invade el estatus del otro y rom-

${ }^{26} C f$. Ricottilli 2000, pp.170-171, que destaca la inserción de una descripción gestual referida al auditorio, en la cual el gesto puede definirse como un regulador que se destaca en el silencio y en la espera de la narración de Eneas.

${ }^{27}$ Rhet. Her.3.27: acri et defixo aspectu.

${ }_{28}$ Prueba de ello la encontramos en Cic.De orat.2.225 (coniectis oculis, gestu omni ei inminenti). Por otra parte, Rizzini (1998, pp.16-17) apunta que los testimonios iconográficos reflejan la postura y la mímica establecidas por la retórica. En este sentido, destaca Rizzini la aportación de Neumann (1965, p.15) quien llama la atención sobre la decoración de una copa del siglo V a.C. conservada en el British Museum que representa la intervención de Ulises en la embajada a Aquiles narrada en el libro 9 de la Ilíada, en la que se observa una intensa mirada de Ulises sobre Aquiles.

${ }^{29}$ Otros ejemplos de la mirada como reguladora del discurso: la mirada fija de Turno sobre Camila en VERG.Aen.11.507 (Turnus ad haec oculos horrenda in uirgine fixus); las miradas de todos los presentes sobre una persona esperando sus palabras en Liv.40.12.2. (coniecti eorum, qui aderant, oculi in Demetrium sunt, uelut confestim responsurus esset), APUL.Met.2.20 (omniumque ora et optutus in unum quempiam angulo secubantem conferuntur) y Plin.Epist.7.6.12 (Tum ego, cum omnes me ut diu responsurum intuerentur).

${ }^{30}$ Cairns (2005, p.129) señala cómo el hablante de THEOC.5.35-37 considera una afrenta que un antiguo pupilo fije la mirada en él, directamente, cara a cara. 
pe los protocolos normales de la interacción ocular, por lo que comporta una actitud amenazante. ${ }^{31}$ En este sentido, como expresión de dominio entre individuos de diferente rango, podemos citar el pasaje en que Suetonio (Aug.79.3) describe al emperador Augusto. Cuenta el biógrafo que al emperador, que creía que sus ojos estaban dotados de fuerza casi divina, le gustaba que, cuando miraba fijamente a alguien, éste bajase la vista como si fuera la luz del sol:

oculos habuit claros ac nitidos, quibus etiam existimari uolebat inesse quiddam diuini uigoris, gaudebatque, si qui sibi acrius contuenti quasi ad fulgorem solis uultum summitteret;

«Sus ojos eran vivos y brillantes, y le gustaba incluso hacer creer que en ellos había una especie de fuerza divina, disfrutando si, al mirar a alguien fijamente, éste bajaba el rostro como ante el resplandor del sol;» (Ramírez de Verger 1992, p.264)

Esta actitud amenazante de la mirada fija puede concretarse igualmente en el rechazo o la ira. ${ }^{32}$ Así, en la narración que en Curcio 7.5.24 se hace de la entrega de Beso a Alejandro, aquel, deseoso de vengarse de los conspiradores (auidus explendi supplicii), fijó en ellos su mirada, dispuesto a atacarles sin poderse contener: Quos Bessus truci uultu intuens consurgit manibus non temperaturus.

De todas maneras, mirar directa y fijamente a menudo expresa no una actitud amenazante respecto a otro sino la seguridad en uno mismo, el sentimiento del propio valor. ${ }^{33}$ El gesto lo encontramos usado metafóricamente en Séneca (Dial.2.5.4) para indicar el dominio que la virtud tiene sobre todas las situaciones, tanto favorables como desfavorables; la acción, aunque figurada, de no desviar los ojos refleja la valentía de no amedrentarse ante ninguna circunstancia:

libera est, inuiolabilis, immota, inconcussa, sic contra casus indurat, ut ne inclinari quidem, nedum uinci possit; aduersus adparatus terribilium rectos oculos tenet, nihil ex uultu mutat, siue illi dura siue secunda ostentantur.

«Es libre [la virtud], inviolable, inamovible, inconmovible, tan endurecida ante las circunstancias que no puede ser desviada, mucho menos vencida; mantiene los ojos fi-

${ }^{31}$ Cf. PACVV. Incertae fabulae fragmenta 24 (quid me obtutu terres, mulces laudibus?), fragmento en el que se ha propuesto ver la reacción de Polimnéstor ante la actitud desafiante de Hécuba en la Iliona (Artigas 2009, p.219). Vid. también Plin.Paneg.34.3 y, para este pasaje, Barton (2002, esp. p.224).

Los escritores fisiognómicos interpretan la mirada fija como una señal de impudicia. $C f$. el anónimo latino De Physiognomonia 94: (Förster 1893, vol. 2, pp.120-121): Impudens homo ita esse debet: oculis patentibus lucidis, palpebris plurimum reseratis, crassis pedibus et manibus, contra intuens, altius se erigens, rubicundus colore, uocis acutae. huiusmodi impudens, iniuriosus homo est. Cf. para la literatura griega Cairns (2005, pp.128-131).

${ }^{32}$ Cf. CIC.Verr.2.5.144 (te animo iniquissimo infestissimoque intuetur); QuINT.Inst. VI, 1, 43 (toruo uultu intueris); Plaut.Capt.557 (Viden tu hunc, quam inimico uoltu intuetur?); Hor.Epod.5.9-10 (quid ut nouerca me intueris aut uti / petita ferro belua?'); SIL.13.374-376 (minaci obtutu toruum contra et furiale renidens).

${ }^{33}$ Cf., para la literatura griega, Cairns 2005, p.131: Od.17.239; X.HG7.1.30; PLU.Dem.29.3-4; y E.Heracl.221. 
jos ante los preparativos más terribles, no cambia nada su rostro bien le parezca la situación dura, bien favorable.» (Codoñer 1984, p.85)

Por otro lado, el gesto de mirar fijamente focalizando sobre una persona puede darse, como antes decíamos, en una relación de gran carga afectiva. Ya hemos apuntado a propósito de la mirada de reojo cómo los gestos con los ojos son fundamentales en las relaciones amorosas. En este contexto el gesto de fijar los ojos está muy atestiguado en los textos latinos, ${ }^{34}$ en especial en el primer momento del enamoramiento. Sin duda influyen en esta estrecha relación entre el deseo-amor y los ojos las teorías materialistas sobre el amor (Gordon 2002, esp. pp.91-92 y Cairns 2005, pp.137-143). Ya advierte Lucrecio que los amantes no se sacian de contemplar el cuerpo querido (4.1002: nec satiare queunt spectando corpora coram). Ovidio, en epist.20.203-208, lo expresa con claridad cuando Aconcio pide a Cidipe que cuente a su madre toda la historia de su enamoramiento desde que la vio por primera vez y su mirada quedó fijada en ella; es la admiración por la belleza contemplada lo que provoca esta mirada fija, que constituye además un signo de turbación (nota certa furoris):

\section{Ordine fac referas, ut sis mihi cognita primum, \\ Sacra pharetratae dum facit ipsa deae, \\ $V t$ te conspecta subito, si forte notasti, \\ Restiterim fixis in tua membra genis, \\ Et, te dum nimium miror, nota certa furoris, \\ Deciderint umeris pallia lapsa meis;}

«Procura contárselo por orden: cómo yo te conocí primero, mientras ella hacía un sacrificio a la diosa portadora de aljaba; cómo nada más verte, si por acaso te diste cuenta, me quedé quieto, fijos mis ojos en tus miembros, y mientras te contemplaba con tan gran admiración -señal inequívoca de mi enajenamiento- cayó el manto de mis hombros deslizándose.» (Cristóbal 1994, p.272)

El gesto de mantener la mirada fija en una persona en virtud del afecto que se siente por ésta se puede encontrar también fuera del contexto de una relación amorosa, ${ }^{35}$

\footnotetext{
${ }^{34}$ Cf. Ov.Met.4.196-197 (Leucothoen spectas et uirgine figis in una, / quos mundo debes, oculos); SUET.Tib.7.3 (contentis et tumentibus oculis prosecutus est); STAT.Silu.5.1.173-175 (immotas obuersa genas); Prop.1.3.19 (sic intentis haerebam fixus ocellis); HoR.Carm.1.36.17-18 (omnes in Damalin putris deponent oculos), en que se mira fijamente a una mujer a causa de la atracción que se siente por ella. Para la importancia del contacto ocular y las miradas recíprocas entre amantes en la literatura griega, $c f$. Cairns (2005, pp.132 y 147, nota 33): A.Suppl.1003-1005, E.Med.1146, A.R.3.287-288, y 1008-1020, S. fr. 474 (Radt 1977, pp.383-384); Pl.Phdr.255ce; X.Hier.1.35; Plu.5.7, 681BC (vol. IV Teubner); Charito 1.1.6; X.ЕPH.1.3.1; ACH.TAT.1.9.4; HLD.3.5.5.

${ }^{35} \mathrm{Cf}$., como ejemplos de esta mirada en relaciones de estrecha amistad y parentesco, VERG.Aen.1.717-719 (haec oculis, haec pectore toto / haeret), en que Dido fija la mirada en un falso Ascanio que es, en realidad, el dios Cupido (Ricottilli 2000, p.42) y Ov.Met.2.502 (immotosque oculos in se sine fine tenentem), en que Calisto, convertida en osa, clava sus ojos en su hijo Arcas, que, sin reconocerla, se dispone a matarla (Corbeill 2004, p.147). También en la literatura griega: Od. 11.450-453; E.Alc.1133, Io.732, Ph.454-464, Med.10381040, Or.1082, I.A.637, 648 y 1238. Cf. Cairns (2005, pp.133 y 147, notas 37 y 38).
} 
expresando así una consideración positiva del destinatario de la mirada. ${ }^{36}$ Así lo leemos en Claudiano (24.3.195-201) al describir el aprecio que por el cónsul Estilicón sentía el pueblo, que no se cansaba por ello de mirarlo:
... exultant auidi, quocumque decorus
conspiciare loco, nomenque ad sidera tollunt:
nec uaga dilecto satiantur lumina uultu, seu circum trabeis fulgentibus aureus intres, seu celebres ludos, solio seu fultus eburno cingas iure forum, denso seu turbine uulgi circumfusa tuae conscendant rostra secures.

«Saltan ansiosos por contemplarte en cualquier lugar que se te vea con tu hermosa figura, elevan a los astros tu nombre y sus miradas errantes no se cansan de observar el rostro que aman, ya si entras áureo por la resplandeciente trábea en el circo, ya si estás presente en la celebración de los juegos o, sentado en tu rostro de marfil, dispensas justicia en el foro, o si tus fasces suben a la tribuna rodeada por una apretada multitud de gente.» (Castillo 1993, p.121)

En este sentido, el verbo contemplor en latín encierra en su significado no solo la acción de mirar fijamente, sino también de hacerlo con complacencia, de modo que contemplor significa por sí mismo 'mirar atentamente y de grado', ${ }^{37}$ expresando por tanto una consideración positiva del destinatario de la mirada. A modo de ejemplo, lo vemos en el texto siguiente (Plaut.Epid.622-624) en el que Estratípocles insta a Epídico a contemplar a una muchacha (uid. García Hernández 1976, pp.80-83):

STR. Haec est. estne ita ut tibi dixi? aspecta et contempla, Epidice: usque ab unguiculo ad capillum summumst festiuissuma. estne consimilis quasi cum signum pictum pulchre aspexeris?

«ESTR. Sí, es así. ¿No es así como te dije? Mira y contempla, Epídico: de pies a cabeza, un encanto. No parece sino que se está mirando un lindo cuadro.» (González Haba 1996, p.140)

\footnotetext{
${ }^{36}$ Asimismo la mirada fija como expresión de la alta consideración que el pueblo tiene hacia un prócer se lee en Cic.Manil.41 (Itaque omnes nunc in eis locis Cn. Pompeium sicut aliquem non ex hac urbe missum, sed de caelo delapsum intuentur); Deiot.20 (Obsecro, Caesar, repete illius temporis memoriam, pone illum ante oculos diem, uoltus hominum te intuentium atque admirantium recordare); Liv.3.69.3 (ibi uero in Quinctium omnes uersi ut unum uindicem maiestatis Romanae intueri); y SEN.Clem.1.19.8 (Nec alio animo rectorem suum intuetur, quam si di immortales potestatem uisendi sui faciant, intueamur uenerantes colentesque).

En Quint.Inst.12.10.65, esta mirada expresa la consideración hacia aquel que posee el arte de la elo-

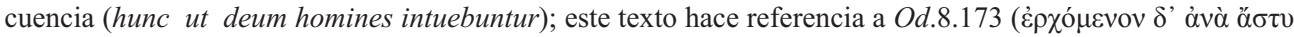

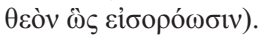

Igualmente, en la literatura griega, la mirada expresa una consideración positiva de los demás: Od.8.459, Hes.Th.84-93. $C f$. Cairns (2005, p.131).

${ }^{37}$ Este es el significado que propone García Hernández (loc. cit.), quien considera que este verbo añade, a la fijación visual de tueor y sus compuestos, «la noción de 'recreación y goce estético de la mirada'». Aunque el objeto de contemplor puede ser animado o inanimado, García Hernández apunta que debe considerarse siempre inanimado puesto que la acción consiste «en contemplar la belleza de las cosas (lo bello / feo) y el valor de las mismas (lo bueno / malo)» (loc. cit., p.82).
} 
De modo similar, puede ocurrir igualmente que el destinatario de esta mirada fija que comunica agrado sea un objeto. ${ }^{38}$ En muchas ocasiones las emociones que comunican esta mirada son no solo agrado sino también asombro. ${ }^{39}$ Así, en Valerio Máximo (5.4.1.ext.), se fijan los ojos en una pintura, y esa mirada comunica el asombro (stupent) y la admiración (admiratione) de quienes contemplan el cuadro:

haerent ac stupent hominum oculi, cum huius facti pictam imaginem uident, casusque antiqui condicionem praesentis spectaculi admiratione renouant, in illis mutis membrorum liniamentis uiua ac spirantia corpora intueri credentes.

«Los ojos humanos miran con atención y se quedan atónitos cuando contemplan un cuadro que representa un hecho semejante y renuevan, con la admiración de un espectáculo que tenemos ante la vista, la escena de un acontecimiento antiguo y les parece ver en aquellas figuras de mudos miembros cuerpos que aún viven y retiran.» (Martín Acera 1988, p.312)

Ciertamente el asombro, mezclado o no con otros sentimientos, es una más de las emociones que puede comunicar la mirada fija. ${ }^{40}$ En un pasaje de Virgilio (Aen.11.120121) se narra cómo los latinos se han quedado estupefactos tras un discurso de Eneas.

\footnotetext{
${ }^{38}$ Fijar la mirada en un objeto puede ser una mera acción sin función comunicativa que se realiza simplemente para observar algo con detenimiento. Es lo que sucede en Bell.Afr.26.4, en que César mira fijamente el mar esperando la llegada de su ejército (oculos mentemque ad mare depositos derectosque haberet) o en LuCAN.9.1035-1036, en que César, cuando ve la cabeza de Pompeyo, fija los ojos en ella para asegurarse de que se trata, efectivamente, de su enemigo: non primo Caesar damnauit munera uisu / auertitque oculos; uultus, dum crederet, haesit; "César no abominó del regalo al primer golpe de vista ni apartó los ojos; mantuvo fija la mirada, hasta estar bien seguro» (Holgado 1984, p.410). Cf., para este pasaje, Eldred (2002, p.79). Cf. también LuCAN.3.4 (non flexit lumina terra) y VERG.Aen.5.853 (oculosque sub astra tenebat).

${ }^{39} \mathrm{Cf}$. para la expresión de admiración y asombro VeRG.Aen.1.495 (dum stupet obtutuque haeret defixus in uno), donde Eneas fija la mirada en las escenas de la guerra de Troya representadas en el templo dedicado a Juno en Cartago ( $c f$. , con referencia a este texto, Lobe 1999, p.58, donde se interpreta también la mirada de Eneas como expresión de su asombro). La admiración es igualmente el sentimiento expresado por la mirada fija en PRUd.Psych.337 (defixis inhiant obtutibus). En VAL.FL.4.323-324, Pólux mira fijamente (longo comminus obtutu mirans tenet) al derrotado Amico admirado ante su corpulencia. Cic.Rep.6.18 (quae cum intuerer stupens).

${ }^{40}$ En este sentido, es significativo el comentario de Servio a Eneida 10.446, verso en que Virgilio describe cómo Palante ha quedado perplejo ante la irrupción de Turno con la expresión miratus stupet in Turno. El comentario de Servio nos da la descripción física de la estupefacción de Palante ante Turno: fija la mirada en Turno (intueor), con estupefacción: 'stupet in Turno'id est in Turnum intuens. Otros ejemplos de la mirada fija sobre una persona como expresión del mismo sentimiento de estupor aparecen en: STAT.Theb.1.493 (obtutu gelida ora premit cf. v. 490-492: stupet omine tanto / defixus senior, diuina oracula Phoebi / agnoscens monitusque datos uocalibus antris); VAL.MAX.9.9.2 (...qui oculis paulisper haesit inopinato iacentis ducis spectaculo attonitus...); Cic.De orat.3.53 (quem stupefacti dicentem intuentur?).

Señalamos ejemplos en los que el asombro no va unido al sentimiento de agrado: en LuCAN.7.786-789, es también el asombro lo que provoca que Pompeyo fije su mirada en los campos de Farsalia después de la batalla y aquí el asombro va unido al dolor producido por la visión de la masacre que allí ha tenido lugar. En Petron.49.3 (deinde magis magisque Trimalchio intuens eum) la mirada refleja el asombro y la indignación fingidos. En SiL.17.341-346, la mirada fija de asombro se mezcla con un sentimiento de tristeza y desagrado ante lo que contempla. Así, la mirada fija y torva de Juno refleja su angustia ante la situación de los cartagineses, como prueban las palabras de Júpiter: Haec procul aeria speculantem nube sororem / ut uidit diuum genitor maestosque sub acri / obtutu uultus, sic ore effatus amico est: / 'Qui te mentis edunt morsus? da noscere coniunx. / num Poeni casus ducis et Carthaginis angit / cura tuae?
} 
Éste, tras haberles concedido una tregua para enterrar los cuerpos dispersos por el llano, lamenta, en un emotivo parlamento, la guerra que les enfrenta. Tras sus palabras, los latinos, mirándose entre sí, mantienen fija la vista en los demás, ${ }^{41}$ reflejando con este gesto la sorpresa y, poniéndose de relieve, de esta manera, la importancia de las palabras de Eneas: illi obstipuere silentes / conuersique oculos inter se atque ora tenebant. «Ellos quedaron en silencio estupefactos y mantenían fijos los ojos y los rostros mirándose los unos a los otros.. ${ }^{42}$ (Echave-Sustaeta 1992, p.485)

Esta misma mirada fija entre un grupo de personas se encuentra también en algunos textos en que el sentimiento comunicado por ese gesto no es tanto la estupefacción, como en el caso anterior, sino, más bien, la expectación. Así, en contextos en que se espera la reacción de alguien, los presentes se miran fijamente unos a otros, expectantes y esperando que uno de ellos actúe. Esta es la situación que describe el siguiente texto de Livio (26.18.6). En Roma se convocan comicios para elegir un procónsul para Hispania después de que en solo un mes hubieran caído dos generales. En el Campo de Marte, ante los ojos de los ciudadanos, los magistrados se miran unos a otros esperando que alguien manifieste su disposición al cargo: ${ }^{43}$

maesta itaque ciuitas prope inops consilii comitiorum die tamen in campum descendit; atque in magistratus uersi circumspectant ora principum aliorum alios intuentium fremuntque adeo perditas res desperatumque de re publica esse ut nemo audeat in Hispaniam imperium accipere,

«La ciudadanía, por tanto, estaba abatida y sin saber qué hacer, pero no obstante bajó al Campo de Marte el día de los comicios; vuelta hacia los magistrados, observaba los rostros de los ciudadanos principales, que a su vez se miraban unos a otros, y murmuraba que la situación era tan deseperada y se confiaba tan poco en la supervivencia del Estado que nadie tenía el valor de hacerse cargo del mando supremo en Hispania;» (Villar-Fernández Nieto 1993, p.43)

Finalmente, el gesto de fijar los ojos en una persona o en un objeto puede realizarse con la finalidad de señalar aquello que se está mirando, como ya ocurría con la mirada de reojo, aunque en ésta se añadía el componente del disimulo. En efecto, con una

\footnotetext{
${ }^{41}$ Otros textos en que el estado de estupefacción de un grupo de personas es expresado mediante el gesto de mirarse fijamente las unas a las otras son: Liv.9.2.11 (...stuporque omnium animos ac uelut torpor quidam insolitus membra tenet, intuentesque alii alios, cum alterum quisque compotem magis mentis ac consilii ducerent, diu immobiles silent), 9.5.8 (alii alios intueri), y PETRON.19.1 (ac modo nosmetipsos, modo mulieres intueremur).

${ }^{42}$ Ricottilli (2000, pp.155-156), tras apuntar que la gestualidad aquí descrita aparece una sola vez en todo el poema, destaca que enfatiza la sorpresa de los latinos y señala, a través de los gestos de éstos, la importancia del discurso de Eneas. La gestualidad asumiría, de este modo, la función de poner de relieve un discurso directo. $C f$. igualmente Liv.33.32.7 (uix satis credere se quisque audisse et alii alios intueri).

${ }^{43}$ Cf. Liv.32.20.1 (diu silentium aliorum alios intuentium fuit), donde, una vez reunida la asamblea, se miran en silencio unos a otros en espera de que alguien presente una propuesta. En TAC.Ann.13.16.3 el valor expresivo-comunicativo de la mirada fija es el mismo, aunque, en este caso, todas las miradas se focalizan en una sola persona. Se trata del pasaje en que, tras el envenenamiento de Británico, aquellos de los presentes que intuyen lo sucedido miran fijamente a Nerón esperando su reacción, o su respuesta (at quibus altior intellectus resistunt defixi et Neronem intuentes).
} 
mirada hacia una persona, objeto o lugar se puede realizar un gesto deíctico, con el cual se señala esa persona, objeto o lugar y se da así una información sobre el contexto físico del que realiza el gesto. En este caso el gesto no nos comunica sentimientos o emociones del emisor sino que nos informa sobre su mundo circundante y asume, por tanto, un valor demostrativo.

Los textos latinos, al referirse a esta mirada, aluden al significado del gesto, a su función deíctica, pero no al modo en que se realiza. ${ }^{44}$ Efectivamente las referencias a este gesto en la literatura latina aparecen generalmente expresadas con el verbo notare y signare y sus respectivos compuestos denotare y designare, llevando como complemento instrumental oculis. Los textos no nos proporcionan información sobre el modo de realización del gesto con el que se señala, si bien podemos entender que se trata de dirigir la mirada hacia la persona o cosa que se pretende indicar y focalizarla en ello. Cabe advertir, además, que, al señalar el emisor el objeto o la persona en cuestión, informa al destinatario de la presencia de aquello que se señala y que las inferencias de esa presencia o bien ya son conocidas o bien son deducidas por el destinatario.

El gesto de señalar con los ojos puede ser una manera más de señalar, que refuerza a otros gestos realizados con la cabeza y con las manos, como ocurre en Apuleyo (Met.3.12): sic omnium oculis, nutibus ac denique manibus denotatus inpos animi stupebam. «Todos me señalaban con la vista, con el gesto, con la mano: yo quedé aturdido y sumido en estúpido letargo.» (Rubio 1978, p.96)

En otros casos los ojos son suficientes para realizar la acción deíctica, sin que participe en ella ninguna otra parte del cuerpo. Esto puede observarse en Cicerón, $\mathrm{Ca}$ til.1.2, donde el arpinate, pese a no describir tampoco el movimiento de los ojos, refiere cómo Catilina designa con la mirada a aquellos que deben morir: uiuit? immo uero etiam in senatum uenit, fit publici consili particeps, notat et designat oculis ad caedem unum quemque nostrum. «¿Que si vive? Mucho más: incluso se persona en el senado; participa en un consejo de interés público; señala y destina a la muerte, con sus propios ojos, a cada uno de nosotros. $\rangle^{45}$ (Aspa 1995, p.302). En este pasaje, además de atestiguar la mirada como gesto deíctico, se nos informa de las inferencias que conlleva la mirada para el destinatario del gesto: la muerte de la persona señalada con la mirada. ${ }^{46}$

También es la mirada el único gesto con el que se señala en el siguiente texto virgiliano (Aen.12.1-4), en que los latinos, fuertemente abatidos por la difícil situación en la que se encuentran, señalan con los ojos a Turno y le reclaman que cumpla la promesa de enfrentarse él solo a Eneas, que había formulado en 11.434-444:

\footnotetext{
${ }^{44}$ Apunta Sittl (1890, p.54) que la deíxis puede residir a veces en la dirección de la mirada aunque esta forma de señalar constituye una excepción a la regla general, representada por el movimiento de la mano. El ejemplo que aporta Sittl no ofrece una descripción pormenorizada de esa mirada: huic -me autem intuebatur(SulP.SEV.Dial.3.3.5). No obstante, puede entenderse, por el uso del verbo intueor, que se trata de una mirada prolongada.

45 Aunque tampoco se describe el movimiento de los ojos, podemos entender que aparecen también referencias a la acción de señalar con la mirada en Sen.Ben.3.17.2 y Ag.898-899.

${ }^{46}$ Igualmente en CURT.9.7.25 (coniectum oculorum, quibus ut fur destinabatur, Dioxippus ferre non potuit) con la mirada fija se acusa de ladrón a Dioxipo, quien, no pudiendo soportar esa acusación, falsa, se suicida.
} 
Turnus ut infractos aduerso Marte Latinos

defecisse uidet, sua nunc promissa reposci,

se signari oculis,

«Ve Turno a los latinos quebrantados por el adverso giro de la guerra, desfallecido su ánimo. Claman porque les cumpla las promesas señalándole todos con los ojos.» ${ }^{47}$ (Echave-Sustaeta 1992, p.517)

En el comentario a este pasaje Tiberio Donato apunta que Turno infiere del gesto de los latinos la petición de que cumpla su promesa: Turnus...colligens ex ratione gestorum reposci pollicitationem suam.

En segundo lugar, como ya hemos mencionado, se puede fijar la vista en un punto sin focalizar. Este gesto puede ser indicio de concentración y reflexión. Los textos fisiognómicos así lo exponen: «si la mente está muy concentrada en un pensamiento, también la mirada está fija». (Pseudo-Aristóteles, Physiognomicon 813a [Förster 1893, vol. 1, p.84])

Cicerón, en De orat.3.17, describe cómo Craso tenía la mirada inmóvil cuando pensaba:

in primis hoc a se Cotta animaduersum esse dicebat omne illud tempus meridianum Crassum in acerrima atque attentissima cogitatione posuisse seseque, qui uoltum eius, cum ei dicendum esset, optutumque oculorum in cogitando probe nosset...

«Así pues, cuando antes de mediodía se retiraron a descansar un poco, Cota decía haber advertido desde el principio que Craso, durante ese rato del mediodía había estado en actitud de profunda y atenta meditación y que él, que conocía perfectamente su expresión cuando tenía que pronunciar un discurso y su mirada inmóvil mientras pensaba...» ${ }^{48}$ (Iso 2002, pp.380-381)

Puede ocurrir incluso que el gesto se haga de forma intencionada para simular un estado de concentración. Así lo leemos en Plinio el Joven (Epist.2.20.3), donde Régulo, con la intención de timar a la moribunda Verania finge un estado de meditación tras el cual le comunica que va a superar la enfermedad: componit uultum, intendit oculos, mouet labra, agitat digitos, computat. Se trata, pues, de una gestualidad simulada y los gestos exteriorizadores que realiza Régulo y que denotan un estado de meditación son: poner cara de circunstancias, fijar los ojos, mover los labios, agitar los dedos, contar.

\footnotetext{
${ }^{47}$ Ricottilli (2000, p.86) cita este texto como ejemplo de que en la Eneida los gestos, tanto deícticos como emblemáticos, además del valor referencial, presentan también una «particular carga afectiva que tiende a evidenciar su dimensión relacional».

48 Otros ejemplos del gesto de fijar la mirada como indicio de concentración y reflexión: VERG.Aen.6.156158 (Aeneas maesto defixus lumina uultu / ingreditur linquens antrum, caecosque uolutat / euentus animo secum) y Aen.8.520-522 (Vix ea fatus erat, defixique ora tenebant / Aeneas Anchisiades et fidus Achates, / multaque dura suo tristi cum corde putabant). Cf. Ricottilli (1992, pp.197 y 213). Insiste Ricottilli en este trabajo en la función de la representación gestual de la meditación en la Eneida para evidenciar la importancia de los discursos directos. Cf. Plin.Nat.7,22, como ejemplo extremo del gesto en un estado de concentración (philosophos eorum ... perstare contuentes solem inmobilibus oculis).
} 
También puede darse el mismo gesto en respuesta a un estado de estupefacción. ${ }^{49}$ En Epist.1.6.9-14 Horacio, al advertir a Numicio que el perder la capacidad de asombro es una de las claves de la felicidad, describe precisamente la postura provocada por un estado de estupefacción (animoque et corpore torpet) en alguien que tiene miedo a perder los bienes que posee: los ojos fijos (defixis oculis) sin mirar, sin focalizar:
qui timet his aduersa, fere miratur eodem
quo cupiens pacto; pauor est utrubique molestus,
inprouisa simul species exterret utrumque.
gaudeat an doleat, cupiat metuatne, quid ad rem,
si, quicquid uidit melius peiusue sua spe,
defixis oculis animoque et corpore torpet?

«El que teme lo contrario de esos bienes se conturba casi del mismo modo que el que los desea. El miedo angustia al uno y al otro. La posibilidad de algún imprevisto aterra a ambos por igual. Que alguien goce o sufra, que desee o que tema, ¿qué importa, si cualquier cosa que vea, ya sea mejor o peor de lo que espera, extraviados los ojos, lo deja aturdido en su cuerpo y en su espíritu?» (Cuatrecasas 1992, p.277)

Por otro lado, la gestualidad puede usarse para disimular los sentimientos. Ello ocurre, por ejemplo, en la Eneida (4.331-332) donde Eneas fija la mirada para controlar sus emociones, hasta el punto de esconderlas completamente y fingir una impasibilidad total ante Dido: Dixerat. ille Iouis monitis immota tenebat / lumina et obnixus curam sub corde premebat. «Le habla así. Él siguiendo el consejo de Júpiter mantiene inmóviles los ojos y acalla a duras penas su dolor en lo hondo del pecho.» (Echave-Sustaeta 1992, p.250). Aquí la inmovilidad de la mirada de Eneas es fingida para esconder su verdadero estado de ánimo, su sufrimiento frente al dolor de Dido y por ello el verdadero afecto que siente por ella, afecto que sacrifica para seguir los mandamientos de Júpiter. De este modo, Eneas no solo debe sacrificar sus sentimientos, sino también la posibilidad de expresarlos ante la reina de Cartago. Se pone especialmente de manifiesto aquí la importancia de la consideración pragmática que ha de tener en cuenta la intencionalidad del productor del gesto. ${ }^{50}$

A modo de recapitulación de lo expuesto sobre la mirada fija, hemos distinguido dos maneras de fijar los ojos: focalizando la mirada en alguien o en algo o sin focalizarla.

Hemos analizado, en primer lugar, el gesto de fijar los ojos focalizando sobre alguien, es decir, mantener la mirada sobre alguien de forma más o menos prolongada. Hemos visto cómo este tipo de mirada se usa como regulador del discurso puesto que, como es bien conocido, los contactos oculares son básicos para mantener la interac-

49 Cf. también SEN.Ag.237-238: sed quid trementes circuit pallor genas / iacensque uultu languido optutus stupet? Cf. como ejemplo del gesto utilizado para reflejar el miedo VerG.Aen.7.446-447, (Lobe 1999, p.49). Como ejemplo en la literatura griega: АCH.TAT.3.15.

50 Vid. Ricottilli 2000, pp.30, 87, 92, 94-95, 97 y 101. Establece igualmente el paralelo con Od.19.209-212, donde se encuentra la misma disimulación/simulación gestual. Cf. también sobre este pasaje, Lobe (1999, p.140). 
ción social en la comunicación humana, en especial porque inician la comunicación y regulan los turnos de palabra, aunque cabe decir que en general estos movimientos oculares reguladores son breves e interrumpidos. Fuera de esta función reguladora, la mirada fija de larga duración acostumbra a darse en diversas circunstancias: por un lado, en situaciones de amenaza o agresión, cuando una persona sostiene la mirada sobre otra para expresar superioridad y dominio -en especial cuando la emite un sujeto de más alto rango que el receptor-, o para expresar rechazo o ira o, incluso, la seguridad de uno mismo; y, por otro lado, la mirada fija se da como señal del grado de intimidad y aprecio entre los sujetos, como puede ser entre enamorados. Esta mirada fija, sobre todo en el primer momento del enamoramiento, puede responder a un estado de admiración o asombro que la visión de la belleza del amado puede provocar. También fuera del ámbito amoroso, se encuentran en la literatura latina ejemplos de la mirada fija como expresión de la valoración positiva que una persona u objeto provoca en aquel que lo contempla. Además, como hemos visto, el asombro que comunica la mirada fija puede responder al agrado de lo que se contempla, pero también a otros sentimientos ligados al desagrado. Igualmente la mirada fija entre un grupo de personas comunica un estado de expectación. Por último, la mirada focalizada puede asimismo tener una función deíctica.

En segundo lugar, se fija la vista en un punto sin focalizar, generalmente para no distraer el pensamiento y lograr una mayor concentración. El gesto, por tanto, puede ser indicio de recogimiento y reflexión o bien se da en respuesta a un estado de estupefacción o miedo. Igualmente, y también para no distraer el pensamiento y lograr una mayor concentración, puede incluso fijarse la mirada en un punto sin focalizar para controlar las emociones y disimularlas, de modo que el gesto puede ser un indicio de disimulo.

Así pues, retomando la aseveración inicial sobre los ojos: «espejo del alma sí, pero también de la mente, de nuestra identidad y hasta un espejo del mundo» (Poggi 2006, p.85), podemos precisar que al grupo de informaciones sobre el mundo pertenece la denominada mirada deíctica, con la que se señala aquello que se está observando. La función demostrativa de los ojos puede realizarse a través de dos movimientos diferentes del iris: fijando los ojos en aquello que se quiere señalar y mirando de reojo el objeto o la persona sobre la cual se quiere llamar la atención.

El segundo grupo de significados que pueden proporcionarnos los gestos que aquí nos ocupan es el constituido por aquellos que informan sobre la propia identidad. Forman parte de este grupo los gestos de fijar los ojos en alguien o mirar de reojo por encima del hombro, que pueden reflejar una personalidad soberbia o arrogante.

Pero sin duda la mayoría de los gestos que hemos tratado informan sobre la mente de la persona que realiza el gesto. A través de los ojos se recibe información sobre los procesos del pensamiento, sobre la intención comunicativa o bien sobre las emociones. En efecto, hemos encontrado, entre los gestos que expresan los procesos cognitivos, fijar la mirada sin focalizar para reflejar la concentración; entre los gestos que informan sobre la intención comunicativa debemos mencionar la mirada de reojo para seducir, el gesto de mirar fijamente como regulador del discurso o este mismo gesto para expresar amenaza. Pero, ciertamente, una parte muy relevante de los significa- 
dos que estos gestos comunican son, como es habitual en las expresiones faciales, emociones: hostilidad (mirar de reojo), enamoramiento y deseo (mirar fijamente y mirar de reojo) o admiración y asombro (mirar fijamente).

Sin duda los escritores romanos conocían y plasmaron en sus obras la riqueza comunicativa de la mirada, en sus múltiples facetas y matices.

\section{REFERENCIAS BIBLIOGRÁFICAS}

Aldrete, S. (1999), Gesture and Acclamations in Ancient Rome, Baltimore, Johns Hopkins Universtiy Press.

BARTon, C. (2002), «Being in the Eyes: Shame and Sight in Ancient Rome», en Fredrick, D. (ed.), The Roman Gaze. Vision, Power and the Body, Baltimore \& London, Johns Hopkins Universtiy Press, pp.216-235.

BAggio, M. (2004), I gesti della seduzione. Tracce di comunicazione non-verbale nella ceramica greca tra VI e IV sec. a.C., Roma, «L'Erma» di Bretschneider.

Brilliant, R. (1999), Gesture and Rank in Roman Art, New Haven, Connecticut Academy of Arts.

CAIRns, D. (1993), Aidos. The Psychology and Ethics of Honour and Shame in Ancient Greek Literature, Oxford, Oxford University Press (reimpr. 2002).

CAIRns, D. (2005), «Bullish looks and sidelong glances: social interaction and the eyes in Ancient Greek culture», en CAIRNS, D. (ed.), Body Language in the Greek and Roman Worlds, Swansea, Classical Press of Wales, pp.123-155.

Corbeill, A. (2004), Nature embodied. Gesture in Ancient Rome, Princeton \& Oxford, Princeton University Press.

EKMAN, P. - FrIESEN, W.V. (1969), «The Repertoire of Nonverbal Behavior: Categories, Origins, Usage, and Coding», Semiotica 1, pp.49-98.

Eldred, K.O. (2002), «This Ship of Fools: Epic Vision in Lucan's Vulteius Episode», en Fredrick, D. (ed.), The Roman Gaze. Vision, Power and the Body, Baltimore \& London, Johns Hopkins Universtiy Press, pp.57-85.

Evans, E.C. (1950), «A Stoic Aspect of Senecan Drama: Portraiture», TAPhS 81, 169-184.

Evans, E.C. (1969), «Physiognomics in the ancient world», TAPhS 59, 5-97.

FornÉs, M. A.- PUIG, M. (2010), «Apartar y girar los ojos en los textos latinos» Mirtya 25, 7796.

García Hernández, B. (1976), El campo semántico de «ver» en la lengua latina. Estudio estructural, Salamanca, Universidad de Salamanca, Servicio de Publicaciones.

GARcía HernándeZ, B. (1996), «Lat. tueor. Del análisis estructural a la investigación histórica», en Bammesberger, A. - Heberlein, F. (eds.), Akten des VIII. internationalen Kolloquiums zur lateinischen Linguistik, Heidelbeg, C. Winter, pp.385-400.

Gordon, P. (2002), «Some Unseen Monster: Rereading Lucretius on Sex», en Fredrick, D. (ed.), The Roman Gaze. Vision, Power and the Body, Baltimore \& London, Johns Hopkins Universtiy Press, pp.86-109.

Kendon, A. (2004), Gesture. Visible Action as Utterance, Cambridge, Cambridge University Press.

LATEINER, D. (1995), Sardonic Smile: Nonverbal behavior in Homeric epic, Ann Arbor, University of Michigan Press. 
Lobe, M. (1999), Die Gebärden in Vergils Aeneis. Zur Bedeutung und Funktion von Körpersprache im römischen Epos, Frankfurt, P. Lang.

Neumann, G. (1965), Gesten und Gebärden in der Griechischen Kunst, Berlin, Gruyter,

PogGi, I. (2006), Le parole del corpo. Introduzione alla comunicazione multimodale, Roma, Carocci.

Poggi, I. (2007), Mind, Hands, Face and Body. A Goal and Belief View of Multimodal Communication, Berlin, Weidler.

Poggi, I. - Roberto, E. (2007), «Meaningful eyes», en Ahlsen, E. et al. (eds.), Communication-Action - Meaning. A festschrift to Jens Allwood, Göteborg, Göteborg University, pp.325-341.

Poyatos, F. (1994), La comunicación no verbal, 3 vols., Madrid, Istmo.

Poyatos, F. (2004), «Nuevas perspectivas lingüísticas en comunicación no verbal» en Payrató, Ll. - Alturo, N. - Payà, M. (eds.), Les fronteres del llenguatge. Lingüística i comunicació no verbal, Barcelona, PPU, pp.57-91.

PUiG, M. (2007), «La gestualidad facial según los textos latinos: gestos y maneras asociados a la nariz», Latomus 66, 67-79.

RicotTilli, L. (1992), “«Tum breviter Dido voltum demissa profatur» (Aen. 1, 561): individuazione di un «cogitantis gestus» e delle sue funzioni e modalità di rappresentazione nell'Eneide", $M D$ 28, 179-227.

Ricottilli, L. (2000), Gesto e parola nell'Eneide, Bologna, Pàtron.

RizzINI, I. (1998), L'occhio parlante. Per una semiotica dello sguardo nel mondo antico, Venezia, Istituto veneto di scienze, lettere ed arti.

SitTL, G. (1890), Die Gebärden der Griechen und Römer, Leipzig, Teubner.

\section{EDICIONES, TRADUCCIONES Y COMENTARIOS}

AdLer, A. (1931), Suidae Lexicon, vol. 1.2, Leipzig, Teubner.

Agudo, R.M. - Ramírez de Verger, A. (1992), Suetonio. Vidas de los doce Césares, I, Madrid, Gredos.

Artigas, E. (2009), Marc Pacuvi. Tragèdies, Barcelona, Fundació Bernat Metge.

Aspa, J. (1995), Cicerón. Discursos, V, Madrid, Gredos.

Bethe, E. (1967), Pollucis Onomasticon, vol. 1, Stuttgart, Gruyter (reimpr.).

Bretzigheimer, G. (2001), Ovids Amores: Poetik in der Erotik, Tübingen, Gunter Narr.

Castillo, M. (1993), Claudiano. Poemas, II, Madrid, Gredos.

Codoñer, C. (1984), L. Anneo Séneca. Diálogos, Madrid, Editora Nacional.

Cristóbal, V. (1989), Ovidio. Arte de amar. Sobre la cosmética del rostro femenino. Remedios contra el amor, Madrid, Gredos.

Cristóbal, V. (1994), Ovidio. Heroidas, Madrid, Alianza.

Cuatrecasas, A. (1992), Horacio. Obras completas, Barcelona, Planeta.

Echave-Sustaeta, J. de (1992), Virgilio. Eneida, Madrid, Gredos.

FörSTER, R. (1893), Scriptores Physiognomonici Graeci et Latini, 2 vols., Leipzig, Gruyter (reimpr. 1994).

GonzÁlez HabA, M. (1996), Plauto. Comedias, II, Madrid, Gredos.

Harto Trujillo, M. L. (2002), Amiano Marcelino. Historia, Madrid, Akal. 
Holgado Redondo, A. (1984), M. Anneo Lucano. Farsalia, Madrid, Gredos.

Iso, J. J. (2002), Cicerón. Sobre el orador, Madrid, Gredos.

Latte, K. - Hansen, P. A. (2005), Hesychii Alexandrini Lexicon, vol. 3, Berlin - New York, Gruyter.

MARTín ACERA, F. (1988), Valerio Máximo. Hechos y dichos memorables, Madrid, Akal.

RadT, S. (1977), Tragicorum Graecorum Fragmenta, vol. 4: Sophocles, Göttingen, Vandenhoeck \& Ruprecht.

RaInA, G. (1994²), Pseudo Aristotele: Fisiognomica; Anonimo Latino: Il trattato di fisiognomica, Milano, BUR.

Rubio, L. (1978), Apuleyo. El asno de oro, Madrid, Gredos.

Stallbaum, G. (1970), Eustathii archiepiscopi Thessalonicensis commentarii ad Homeri Iliadem, 2 vols., Hildesheim - New York, Olms (1ª ed. 1827-1830).

Van Dam, H. J. (1984), P. Papinius Statius. Siluae, book II: A Commentary, Leiden, Brill.

Villar, J.A. - Fernández Nieto, F.J. (1993), Tito Livio. Historia de Roma desde su fundación. Libros $X X V I-X X X$, Madrid, Gredos. 